light, and easy to use. I have now treated 200 patients by cryotherapy and over the past two years have operated on only four patients, all of whom presented with acute prolapsed piles. All these have been outpatients, and no sedation or anaesthesia has been given.

My method now is first to deal with all the internal piles using the nitrous oxide cryoprobe through a Clifton nrictoscope, and then any skin tags and external plexus lesions are dealt with using the liquid nitrogen probe. The patients go home half an hour after treatment and are reviewed again after about six weeks. Any residual skin tags are then excised under local anaesthesia, again as an outpatient. Discharge is a problem only when external piles are dealt with.

About $15 \%$ of patients have complained of pain and oedema after treatment, and these have been off work for about four days or so. The remainder have had very little postoperative discomfort and have been delighted with the treatment. Only two patients have been admitted, one with a secondary haemorrhage and the other with gross oedema and pain. All the patients have been symptomatically improved after the first treatment, although about $10 \%$ have needed a further freeze to cure their prolapse completely. The follow-up period ranges now up to two years, and there is no real evidence of recurrence.

This method of treatment is quick, safe, and acceptable to both patient and surgeon alike, while the total cost of $£ 1000$ for the two cryoprobes represents at today's prices only five patients being in hospital for one week as a result of their having had a formal haemorrhoidectomy.

Selly Oak Hospital,

H D KaUfMan

Birmingham

\section{Patients or criminals?}

SIR,-The Butler Committee report ${ }^{1}$ raises issues that society cannot any longer avoid. Military violence produces fewer outlets for aggressive tendencies (the nuclear deterrent is too effective) but social violence is increasing. Urban guerrillas, hidden bombs, hijacked aeroplanes, kidnappings of innocent people, and incest and rape are becoming almost commonplace. The traits of character which society would encourage in war time have now to be contained within society itself, and unless the community is to be damaged the harmful elements in these characteristics must be recognised.

Attempts to deal with character disorders have been hampered by the policy of closing psychiatric hospital beds, which policy has been followed by every minister of health since Mr Enoch Powell. This has left no alternative but imprisonment, and yet some forms of character disorder can be successfully treated. These inadequate personalities are not helped by the soul-destroying conditioning processes of prison or secure units. The mere fact of incarceration does not increase the patient's ability to cope with the complex world, and so on release he too often relapses. These patients need competent therapy in general psychiatric hospitals whose staff are trained to help them in their social and interpersonal relationships. They need to be diagnosed long before they become chronic recidivists. The staff require a special training.

Prophylactically schools should take careful note of a child who is not making reasonable progress or is causing repeated disturbance and not forming useful relationships. Forensic psychiatrists are aware that there is a marked difference between character disorders and neurotic adolescent reactions. It is, however, indisputable that some forms of character disorder are incurable-for instance, when coupled with severe brain damage, severe schizophrenia, or severe subnormality. The national security hospitals provide the best answer to the problems posed by such cases, but what answers are to be provided by the regional security hospitals proposed in the Butler report? The committee has thrown an excellent spotlight on one of the major medical and social problems of today, but little useful or radical treatment is recommended. No prototype programme for therapy in these regional units has been suggested. But without a scheduled therapeutic and progressive programme designed to help those patients able to benefit from it the units will be as ineffective as so many addiction units were some years ago.

Lincoln

John Harding Price

1 Report of the Committee on Mentally Abnormal
Offenders, chairman Lord Butler, Cmnd 6244. London, HMSO, 1975.

\section{Conisation and the minipill}

SIR,-The inquiry of Dr Leiman (13 September, $p$ 651) on the contraceptive failure rate in women using the progestogen-only minipill who have undergone cone biopsy of the cervix raises several interesting points.

Sperm transport through the genital tract depends upon the cervical mucus. The removal of the mucus-secreting cells should therefore contribute positively to the efficacy of the low-dose progestogens rather than impair their effectiveness. The progestogenonly contraceptive pills on the market at present all consist of 19-norsteroids, which seem to have a broader action than the earlier progestogen-only preparations, which contained 17-acetoxyprogestogens and whose action was primarily on the cervical mucus. We have recently demonstrated ${ }^{1}$ that the mode of action of the 19-norsteroid norethisterone given as a low-dose progestogen preparation affects not only cervica mucus but also in some women inhibits ovulation and in others disturbs ovarian steroidogenesis. It has also been shown that the subinterval pregnancy rate of this type of hormonal contraception increases with the duration of its use. ${ }^{2}$ Therefore it is more likely that the failures to which Dr Leiman refers are related to the progressively decreasing effectiveness of these preparations rather than an effect of the conisation per se. Furthermore, there is such a limited use for the progestogen-only pills that it is highly unlikely that sufficient data are available in women who have undergone conisation of the cervix to enable Dr Leiman's query to be answered categorically.

\section{MAX EISTEIN}

Department of Human Reproduction and Obstetrics, Department of Human Rep
University of Southampton
1 Elstein, $\mathbf{M}$, et al, British fournal of Obstetrics and Gynaecology. In press.

\section{Breast-feeding and maternal nutrition}

SIR,-The letter from Dr M A Crawford and Miss Barbara Hall (26 July, p 232) concerning the original article by Dr P L Sousa (1 March, p 512) is very much to the point. The essential question is really what makes for successful lactation in terms of volume actually reaching the child's mouth and, a different matter, the composition of the milk.

Successful breast-feeding is mainly a "confidence trick," especially mediated by enhancement or inhibition of the key psychosomatic let-down or milk ejection reflex. The volume of milk produced in the alveoli is mainly related to the amount of sucking stimulation (and hence prolactin secretion) and, to a lesser extent, to the mother's nutritional status. The composition of breast milk is modified by various influences, certainly the mother's nutrition and diet and possibly even genetic factors.

The pharmacology of milk production and ejection is built-in to the human female endocrinological system. However, the use of metoclopramide may perhaps be of value for indirect reasons. Firstly, it may help in initiating the flow of prolactin and thus possibly be an external pharmacological booster for a few days for what would anyhow result from normal inherent reflex mechanisms. Also, in our Western medical philosophy, the respectability of any procedure increases immediately when a chemical therapeutic approach or some similar dramatic and approved method is instituted, with consequent enthusiasm by the physicians and, by contagion, the mother. In fact, Western medicine is basically "linear," with little tolerance or understanding for the "curved" methods that are biologically inherent. Another example of a similar type is the great difficulty that has occurred in accepting the child-spacing effect of lactation amenorrhoea. Western preference is always for positive, clearcut, technological nterventions.

Recently we have been trying to review the situation concerning the volume and composition of human milk in both poorly and well-nourished communities. ${ }^{1}$ We really know rather little-for example, most work on well-fed women was undertaken almost a quarter of a century ago. In fact, infant feeding can be truly understood only as a dyadic phenomenon, the key factors being the mother's nutritional stores and current diet in both pregnancy and lactation. That this is so in poorer parts of the world is increasingly clear. However, women in industrialised countries may in fact need more nutritional attention in pregnancy and lactation than has been appreciated in recent years. Certainly, this is an area of critical significance and importance, and in need of modern reappraisal.

D B JELLIFFE E F P JELlifFe

Division of Population, Family, and

International Health,

School of Public Health,

University of California,

1 Jelliffe, D B, Jelliffe, E F P, and Yamalachili, I, 